\title{
Research on Innovative Design of Traditional Craft Products in the Intelligent Age
}

\author{
WANGLi, ZHANGHai-chao \\ Dalian University of Science and Technology, China \\ Dalian University of Science and Technology, China
}

\begin{abstract}
With the successive emergence of various intelligent technologies and modern information technology in China, it also provides important technical support for the design and manufacture of traditional craft products in China, which helps to realize the design innovation of traditional craft products and enable them to obtain healthy development. In this context, this article will start by clarifying the significance of the application of intelligent technology in the design of traditional craft products, combining specific examples, focusing on a brief analysis and research on the innovative design of traditional craft products in the era of intelligence.
\end{abstract}

\section{Introduction}

Under the impact of various modern craft technologies, traditional craft products can only truly achieve sustainable development if they continuously strengthen design innovation and actively meet the needs of the market and customers. Therefore, it is of great practical significance to study the design and innovation of traditional craft products in the intelligent era. This research can not only provide relevant theoretical references for related researchers, but also provide some practical guidance and help for how traditional craft products can achieve innovative design in the intelligent era.

\section{Significance of using intelligent technology in traditional craft product design}

\subsection{Improve design effectiveness}

In the design of traditional craft products, the introduction of various modern information technologies including computer technology, as well as other related intelligent tool software systems, is very important to improve the design efficiency of traditional craft products and ensure product design quality. In the past, the design of traditional craft products almost completely adopted the manual design method. Not only the design efficiency was very limited, but also various artificial errors were prone to occur. By using intelligent technical means and using various professional intelligent drawing design software and modeling software to replace traditional manual drawing and manual design, it is bound to greatly improve the efficiency of traditional craft product design [1]. While effectively alleviating the working pressure of designers and reducing their workload, they can also complete the batch and precise design of various traditional craft products, making the products have a higher level of design quality.

\subsection{Achieving Design Innovation}

The application of intelligent technology in the design of traditional craft products also has a positive effect on improving the innovation of product design. On the one hand, intelligent technology can break through the limitations of traditional craft product design models and achieve innovative development of product design forms. On the other hand, the intelligent technology has a variety of advantageous functions such as strong interactivity and various forms, which also help to achieve the functional innovation and optimization of traditional craft products. For example, in the design of traditional mold products, by using various intelligent technologies flexibly, it can add intelligent functions such as intelligent display of product information and other voice and automatic adjustments, so that the product can better meet the diverse needs of customers. And thus achieve the fundamental purpose of promoting traditional craft products to achieve sustainable development.

This article surveyed 300 designers on the Internet about important concepts required for traditional crafts design. The results are shown in Figure 2. According to the data in the chart, it is known that nearly $35 \%$ of the designers in the survey believe that in the era of intelligence Traditional handicraft design needs to make tradition more marketable and refined through innovation. In addition, about $20 \%$ of designers believe that traditional handicraft product design needs to fully express the 
personal ideas of designers.

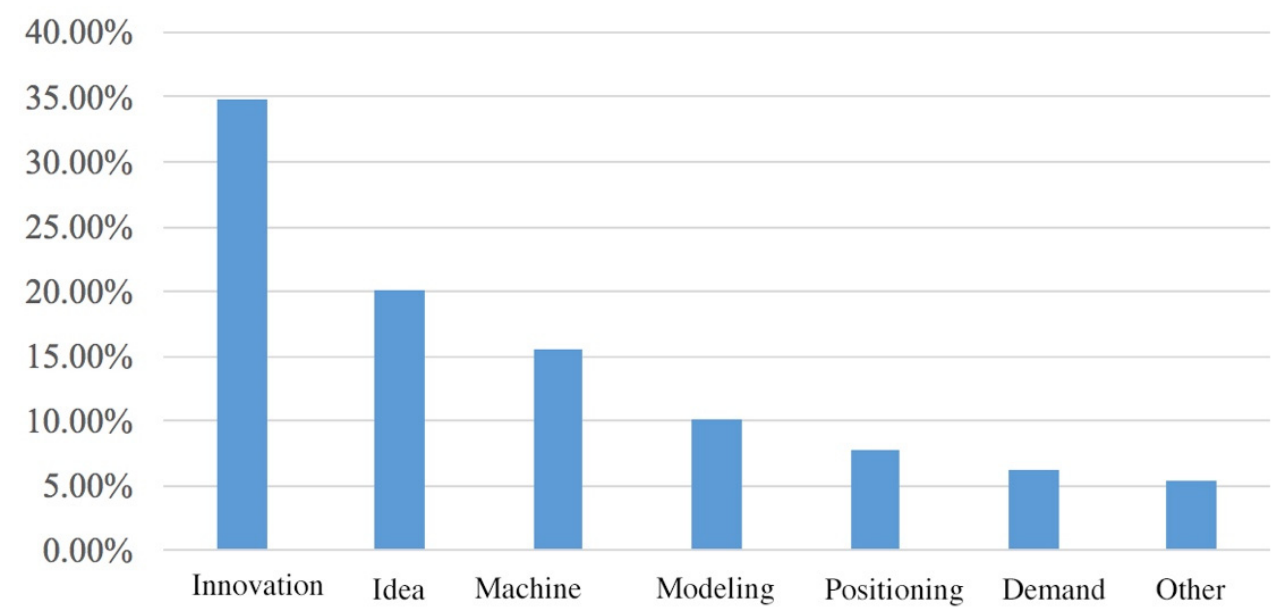

Figure 1. Statistical diagram of the concepts needed for traditional craft products

\section{Innovative strategies based on traditional craft product design in the intelligent era}

\subsection{Relying on intelligent design platform}

According to the above, the use of various intelligent and modern technical means in traditional craft products has an important help in improving the design effectiveness of traditional craft products. Therefore, in the era of intelligence, when relevant staff actually carry out the innovative design of traditional craft products, they also need to flexibly use the intelligent design platform and related tool software based on the product's structural characteristics and design requirements. For example, in the design of a traditional craft product, the designer introduces computer technology, sensor technology, and integrates various existing advantageous resources such as network resources to integrate professional drawing tool software and modeling software. Build an intelligent development and design platform. The intelligent design platform actually belongs to a single-chip microcomputer based on open source code, and uses an intelligent and humanized program control language. There are many universal standard interfaces on its motherboard, which can effectively connect with many sensing devices and control devices such as motors and LEDs. The designer only needs to compile the design requirements and design flow of the craft product into a professional computer program, and the intelligent design platform can complete the design of the traditional craft product automatically, standardly, and in batches [2]. This greatly saves product design time cost and manufacturing cost, and helps the traditional process product to achieve the goal of maximizing economic benefits.

\subsection{Collecting data analysis requirements}

In the traditional product design process, a lot of data information will be generated. In the age of intelligence, relevant staff members flexibly use intelligent technology to actively collect and sort out various information and data generated in traditional product design, and rely on professional data analysis software to conduct in-depth mining and statistical analysis. It can help designers to more comprehensively and accurately understand the design needs of customers and markets for traditional craft products, and then to make scientific and reasonable traditional craft product design schemes more targeted. For example, according to the statistics of 300 questionnaires about the design requirements of customers for traditional craft products based on network statistics, the respondents who knew that they were ordinary tourists accounted for about $40 \%$ of the total number. In the questionnaires they filled out, according to the analysis, the needs of such groups in the design of bamboo weaving products mainly include exquisite style, light and easy to carry, and prominent regional style. Respondents who are collectors or enthusiasts account for about $30 \%$ of the total survey population. The product design needs of this group are mainly based on high design accuracy, artistic aesthetics and unique materials. . Effectively identifying product target groups and using big data resource analysis to understand their specific product design needs can lay a solid foundation for optimizing the innovative design of traditional craft products. Figure 2 shows the quality of good traditional craft works that respondents believe are needed in the survey. 


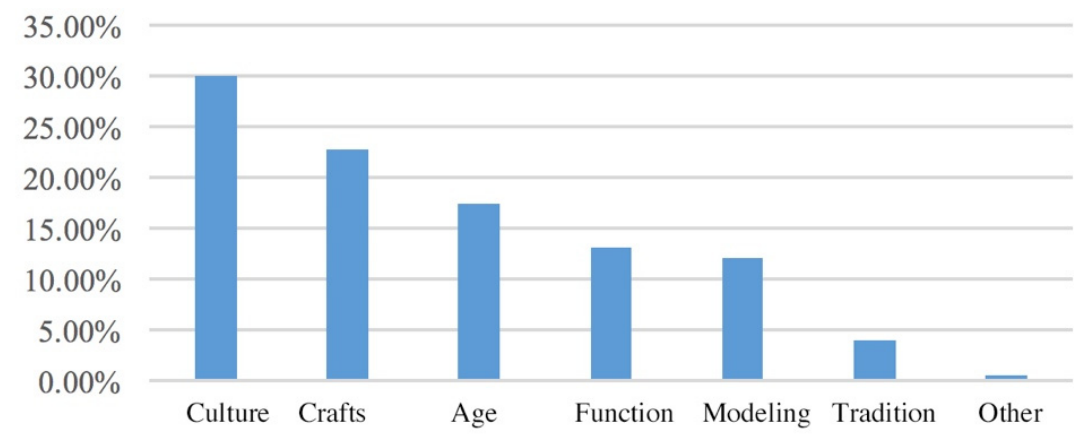

Figure 2. Quality statistics for excellent traditional crafts

\subsection{Public interaction with designers}

In the traditional product design of traditional craftsmanship, almost all the design work was done by the designer, and few designers were able to communicate with customers and other people, so it was easier to cause the designer to block the news, and product design and customer demand Matching situation. In the era of intelligence, the use of open intelligent design systems and various emerging media can effectively strengthen the interaction between designers and customers, product manufacturers, and process learners, and share various aspects of traditional process product design. Information resources [3].In the process of communication, learning and design, the efficient and innovative design of traditional craft products is realized. For example, in the design of a traditional craft product, designers have in the past mostly been limited to unilateral imitation of the existing original shape, structure and color of the product.

At the same time, designers can rely on technologies such as live webcasts, use intelligent digital cameras and video recording equipment, to disclose the design process of the traditional craft product to the public throughout the process, and use methods such as sending bullets and likes to interact with the public, so that it can fully understand the traditional craft product and its design methods, thereby further improving the popularity and social influence of traditional craft products.

It is also worth noting that after completing the design of traditional craft products, designers can also use the interactive tools in the intelligent design platform to track the consumers, manufacturers, etc. of the traditional craft products. Actively understand its feedback on product design, accurately grasp the deficiencies and problems in product design, and then make more targeted improvements to achieve further optimization and innovation of traditional craft products.

\subsection{Products integrate intelligent functions}

In the era of intelligence, the use of various advanced intelligent technologies can also achieve multi-angle development of products. In addition to relying on the intelligent design platform, many designers and their communication with consumers, etc., complete the product modeling design, color design and other aspects of efficient sharing of information resources, and improve the overall product design efficiency. In the selection of materials for traditional craft product design, effective innovation can also be achieved. For example, relevant designers use 3D printing technology or corresponding smart sensors to obtain more materials for product design and effectively control the cost of product design materials. Not only that, with the help of intelligent technology, various new intelligent functions can be incorporated into traditional craft products, making the products more innovative.

For example, in a bamboo weaving craft product, it can only be used to make a sound by tapping and used as a musical instrument for singing and dancing. However, under the application of intelligent technology, designers can use various vibration and ultrasonic sensors, and at the same time use a dedicated intelligent design development board, and use LED lights with self-programming control software. The materials used have also expanded from a single bamboo material such as moso bamboo to various electronic materials and plastics. Users can use voice control, touch control and other methods to make this craft product play various music and audio stories according to actual needs, and can switch to display different lights, integrating sound, light and electricity. On this basis, designers introduce the Internet of Things technology, wireless transmission technology, etc., and connect it with the APP on the mobile phone with the corresponding intelligent hardware and software, so that people can directly use the APP on the mobile phone to remotely process the traditional craft product. intelligent control.

\section{Conclusion}

In the era of intelligence, the application of various modern and intelligent technical methods to the design of traditional craft products not only helps to improve the design efficiency and design quality of products, but also greatly enhances the innovation of traditional craft products. To this end, relevant staff also need to flexibly use various intelligent technologies according to the actual situation of traditional craft products, strengthen the collection and arrangement of various data, and analyze the specific design requirements of the product. On the basis of actively enhancing the efficient interaction between designers and the public, more intelligent functions are incorporated into the product, so that traditional craft products can truly achieve innovative 
design and sustainable development.

\section{References}

1. Wang Tieqiu. Analysis of material selection in industrial design under the background of product intelligence [J].Think Tank Times, 2020 (03): 293294.

2. Shen Xiaowei. Exploring the scientific application of intelligent technology in mold design and manufacturing $[\mathrm{J}]$.International Public Relations, 2020 (01): 235.

3. Zou Jin, Mei Ziyuan, Zhong Wei. Summary of the intelligent development trend of mechanical design and manufacturing [J].Jiangxi Chemical Industry, 2019 (05): 12-14.

4. YAO Bin. Integration of Traditional Handicraft in the Modern Design[J]. Packaging Engineering, 2010, 31 (16): 81-83.

5. ZHANG Duo-duo. Tacit Knowledge: the Microscopic Perspective of Design Innovation Research on Tradi- tional Crafts[J]. Zhuangshi, 2015(6): 117-119. 